\title{
Research on Creation and Technology to Make Large-scale Production of Vertical Greening Wall
}

\author{
Wanlu Luo ${ }^{1}$ and Jianwu Ma,** \\ ${ }^{1}$ Gold Mantis School of Architecture, Suzhou University. Suzhou, Jiangsu, China \\ ${ }^{2}$ Gold Mantis School of Architecture, Suzhou University. Suzhou, Jiangsu, China \\ *Corresponding author
}

\begin{abstract}
This paper introduces a kind of vertical greening wall system on which climbing plants could grow. It emphasizes on illustrating that this system could be manufactured in large scale in factories in advance, and climbing plants can grow on a nurseryland-based structure to become a landscape. It has further discussed at scene installment approaches and post-maintenance management of the vertical greening wall system, which is manufactured in large scale in advance. At last, it has presented that the cost of production of this system is low, the manufacture is rapid, the greening effect is obvious, and the post-maintenance is simple and easy, so it has promoted the development of the vertical greening wall to a great extent.
\end{abstract}

Keywords—greening wall; large-scale; creation; technology

\section{INTRODUCTION}

With the rapid development of urbanization in our country, natural ecological environment has been gradually eroded by reinforced concrete. In order to improve the city's ecological environment and promote the development of vertical greening industry, the government has issued Technical Specification for Vertical Greening Engineering CJJ/T236-2015 in 2015 as the industrial standard. Meanwhile, many scholars in our country has been working about researches on vertical greening technology. Besides the greening wall effect generated by original climbing plants directly clinging to the surface of the wall, there has emerged many new types of vertical greening walls. However, greening walls in the market are expensive and costly, having a high maintenance cost too, only some key cities are using it and it is hard to popularize it to a large scale. Now there has been a greening wall system which can be manufactured in the factory in large scale. Volume production can effectively save the cost of greening wall, and the postmaintenance is simple and easy, so this kind of greening wall is available to be popularized so as to beautify the city's environment and life people's living standard.

\section{THE IMPORTANCE OF FACTORY-MANUFACTURED GREENING WALL}

\section{A. The Effect and Meaning of the Vertical Greening Wall}

The vertical greening wall has all effects of greening plants, especially the landscape effect. It can use limited space to raise the green coverage ratio, fully express the comprehensive effects of plants, and improve the city's environmental aspect. What's more, the vertical greening system is playing an important role in energy-saving and ecological effect. According to statistics, the vertical greening wall can effectively reduce indoor temperature in summer, which is $3.01^{\circ} \mathrm{C}$ on average. This means that it would reduce the consumption of air-conditioners indoor and save energy. It could also raise the indoor temperature of $2-3^{\circ} \mathrm{C}$ in winter, having warmkeeping effect to architectures to some extent, and effectively reducing the cost on heating. Researches have shown that every $0.5^{\circ} \mathrm{C}$ of temperature reducing in summer can save the load of air-conditioner for $8 \%$. Hence, the vertical greening wall is a kind of low-carbon economic way. Greening plants preserve heat, meanwhile, they play fully roles in transpiration, which could increase air humidity. Some climbing plants like costustoot can increase $3.42 \%$ humidity within $1000 \mathrm{~m}^{2}$ air, and campsis grandiflora can increase $2.87 \%$ of that.

\section{General Situation and Problems of The VERTICAL GREENING WALL}

In our country, the industry of vertical greening wall starts quite late, so there have been grand gaps between the industry of vertical greening wall of our country and that of foreign countries, although we have made many achievements in the form of greening, the application of plants, the innovation of material, and maintenance and management in recent years. In the year of 2010, many exhibition halls on the Shanghai EXPO were competing with each other for beauty of "green". Statistics said that among nearly 240 exhibition halls on the EXPO, over $80 \%$ of them made roof greening, vertical greening, and indoor greening. These exhibition halls had concentrated in displaying their latest vertical greening technology, which made the greening thinking step forward from two-dimensional to threedimensional. By using new technology, new material, and new craft, the vertical greening had been shown a wide prospect. For the time being, there have been emerging many technically customized planting wall companies in China who manufacture the greening walls, which consist of the supporting system, irrigating system, cultivation medium, and plants materials, in small scales, based on the customers' needs. This kind of greening wall system rarely makes the common customers satisfied due to the long production phase and high production cost. Shanghai Hainer Company is the earliest technical company that set foot in roof greening and greening system in our country, and the cost budget is based on the area and height of the greening wall, whether or not it needs water-proof material and the category of plants, which is generally 2000 to 5000 yuan per square meter, and some of the greening walls would come to over 10000 yuan per square meter, shrinking back many greening wall amateurs and consumers because of the price. 


\section{MANufacturing THE GREening WALL IN FACTORIES IN A LARGE SCALE}

In order to popularize the application of vertical greening walls, we should seek out a new technology and approach. In agriculture, our country vigorously promoted a standardized production way with high production efficiency, low labor intensity, and standard products based on the production experience from home and abroad so as to achieve the development target of modern "high-efficient agriculture". Being the similar, it is the goal of all people in the industry of greening wall to achieve the standardization of the development of vertical greening wall, and to work out a low-cost greening wall with diversification of green plants, abundance of greening forms, simplification of high altitude operation, and generalization of post-maintenance.

\section{General Situation of Factory Production}

The vertical greening walls can be divided into the climbing type, the modular type, and the paving type greening wall system. Traditional climbing plants greening walls have the strong points of low cost, and easy to be maintained and managed, while their weak points are having the low speed in covering the wall; the modular type and water-cultivated type greening wall systems are abundant in the category of plants, which have a good landscape effect, but being difficult in manufacture and having a quite high death rate.

\section{A SYSTEM GREENING WALL}

At present, AN System is an advanced vertical greening system at abroad, adopting a modular type of full-automatic irrigation system which could be installed simply and independently on any structure and size of architecture. When the production of every type of structural member is over, multiple items as follows should be installed, which include frames, mould layers, waterproof membranes, fixed tracks, $500 \mathrm{~mm} \times 500 \mathrm{~mm} \times 60 \mathrm{~mm}$ ANS modules, irrigation pipes, drain pipes, etc. Using ANS modules to plant needs to base on the design made by Party A in advance before installment, and the landscape will show up forthwith. This way of cultivating seedlings several months before installment could made the death rate and landscape effect of the plants be affected by seasons, and all kinds of force majeures will directly influence the completion time; and being limited by standard base plate, it is quite difficult for manufacturing.

\section{Paving Type Greening Wall System}

The paving type vertical greening wall system represented by the "Vertical Garden" technology invented by a French botanist Patrick Blanc consists of supportive frame, PVC board, cloth felt, automatic spraying system and its accessory members. Without soil or other cultivation medium, the plant directly grows on the blanket of nutrient solution and moisture, the thickness of the whole green wall shrinks greatly, and the structure wall bearing decreases. PVC board is mainly made of polyester, lightweight and anti-impact, and a $10 \mathrm{~mm}$ thick PVC only weighs $7 \mathrm{~kg} / \mathrm{m}^{2}$. The cloth felt cloth of this kind of greening wall system is full of moisture and nutrient solution for a long time, it is easy to rot and go bad, and outdoor plants are difficult to survive in winter.

\section{LARge Scale Vertical GREening WALl System}

\section{A. The Structure of Large Scale Vertical Greening Wall System}

Based on traditional cheap climbing plants greening, it has been developed a greening wall system which can be put into large-scale factorial manufacture. This kind of greening wall retains the strong points of the traditional climbing plants greening walls such as low cost and easy to maintain and manage, what's more, it could grow rapidly and green the wall, which breaks the limitation of the material of walls to the categories of plants.

During the production in the factory in advance, the landscaping wall unit will be transferred to the site and can be assembled in the scene quickly to form a complete green wall system. The greening wall consists of many $1 \mathrm{~m} \times 2 \mathrm{~m}$ unit modules including the assembled frames, assembled frame of climbing vines, and string bags or cloth bags for delivering partial of nutrient soil from the root of climbing plants. The Figure 1 illustrates the greening wall landscape produced by factories.

\section{ChOICE OF PLANTS}

There are many forms of vertical greening. When choosing plant materials, you should first make full use of local plant resources, not only because these plants are most suitable for local growth in terms of ecological adaptability, but also should people consider the light condition and the appearance of frame structure and color form, comprehensively based on above factors shall we choose suitable vines. Based on the characteristics of the frame, the adsorption type and support type of vines are selected as green plants.

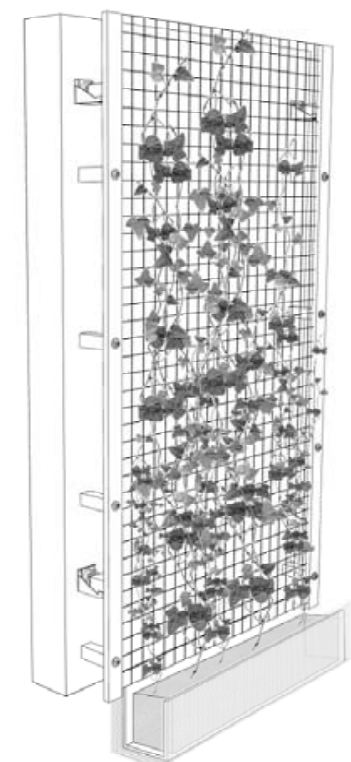

FIGURE I. A DIAGRAM OF THE GREENING WALL LANDSCAPE PRODUCED BY FACTORIES

The stem tendrils of the adsorbent vines of the vines form suction or air rooting, which adsorb on the surface of the supporting material or penetrate into the interior and attach to it 
for growing. The climbing plants with the help of an acetabulum are optional as follows: Parthenocissus tricuspidata, Parthenocissus quinquefolia (L.) Planch, etc. If you choose these climbing plants, the assembled frame should be wrapped by string bags so as to make the absorbent plants climb up. Those plants with aerial roots can be chosen from Hedera nepalensis Var. Sinensis, Campsis grandiflora (Thunb.) Schum, Campsis radicans (L.) Seem, Trachelospermum jasminoides (Lindl.) Lem, Trachelospermum jasminoides'Flame', Trachelospermum asiaticum Ougonnishiki, etc.

The supporting vines include tendrils, twining classes and thorns, which can be grown by the support of the grid. So the main choices include Passiflora coerulea L, Lonicera japonica Thunb, Morden cvs.of Chlimbers and Ramblers, etc.

In order to facilitate the maintenance and management of plants, the selected adsorption type and support type climbing plants should have good tolerance, drought resistance and good growth ability on the basis of fitness, and the common climbing plants such as Hedera nepalensis Var. Sinensis, Trachelospermum jasminoides (Lindl.) Lem, Trachelospermum asiaticum Ougonnishiki, and Campsis radicans (L.) Seem have strong drought resistance ability. Zhou Jun et al have made a comprehensive assessment on the drought resistance ability of above four vines and the result of which shows that the order of the drought resistance ability (from strong to weak) is Hedera nepalensis Var. Sinensis, Trachelospermum jasminoides 'Flame’, Trachelospermum asiaticum Ougonnishiki, and Campsis radicans (L.) Seem.

\section{Technological Analysis}

During the scene manufacture, the weight of landscape's frame and the material of wall surface are the key factors to influence the installment. The dead load of landscape frame include the weight of frame and the weight of plants. The unit weight of landscape frame is approximately $6 \mathrm{~kg} / \mathrm{m}^{2}$, so as to say, the dead load of the greening wall system with landscape frame is not large, and the requirement of wall structure is not strict. The architecture have different kinds of walls such as masonry walls, block walls, brick walls, cement walls, glass curtain walls, etc., and the installment of assembled frame is to use M12 expansion bolts to fix it into the walls. The allowable tension of M12 expansion bolt in M5 mortar brick walls and C10 cement is $10.30 \mathrm{kN}$, and the allowable shearing force of which is $6.90 \mathrm{kN}$, the minimum burial depth is $65 \mathrm{~mm}$. As it goes deeper, the intensity of the buried objects goes up, and the index of allowable tension lifts with it. So it is applicative in masonry walls, block walls, brick walls, and cement walls. The installment of vertical greening on glass curtain walls can depend on the wall adjoining to the curtain wall.

\section{SUMMARY}

The vertical greening is the direction of the development of greening industry in the future, and it is the market's demand to produce the vertical greening industry to a large scale. Experts and scholars should work on the problems of creation and technology on large scale produced vertical greening walls. This paper has provided a kind of large scale rapid assembled vertical greening walls that keeps the strong points of traditional vines greening walls like low cost and easy to be managed, and is able to rapidly climb up the greening wall, breaking the imitation of wall material to plant species, which is a kind of vertical greening wall can be processed in factories in a large scale.

\section{ACKNOWLEDGEMENTS}

Fund Program: Natural Science Foundation of China "Research on Multiple Targets Management Strategy for Park Green Space in Tropical Plateau Monsoon Climate Zone in Yunnan”, Item Number: 51168043

“2016 Jiangsu Regular Institutions of Higher Learning Postgraduates Practical and Innovative Project Item”, Item Number: SJLX16_0538

\section{REFERENCES}

[1] Meng Tao. Practical Research on Vertical Greening's Energy-saving and Reformative Effect on Office Buildings in Shanghai [J]. Shanghai Energy Conservation, 2016, (05):252-255

[2] Dunnett N, Kingsbury N, Planting green roofs and living walls [M]. Timber Press Portland, OR: 2004.

[3] Yin Lifeng, Li Shuhua. The Features of Temperature Distribution of Ultra-low Energy Consumption Green Roofs in Tsinghua University [J]. Scientia Silvae Sinicae, 2007, 43(8):143-147

[4] Shi Qi. Research on Cooling and Humidifying Effect on Different Vertical Greening Approaches in Zhengzhou [D]. Henan Agricultural University, 2006.DOI:10.7666/d.y962621.

[5] Zhu Xiaofang. A New Form of Urban Vertical Greening - From the Perspective of Ecological Landscape [D]. Hebei University of Technology, 2010.DOI:10.7666/d.d113150

[6] He Xiaobo. Research on the Evolution of Vertical Greening Technology and the Design and Practice of Planting Wall [D]. Zhejiang A\&F University, 2013.

[7] Zang Dekui, Zhou Shujun. Climbing Plants and Vertical Greening [J]. China Landscape Architecture, 2000, (05):79-81.

[8] Chen Qing, Cai Yongli, Choice and Settlement of Vines in Urban Vertical Greening [J]. Urban Environment \& Urban Ecology, 2006, (05):26-29.

[9] Zhou Jun, Wu Jincui, Du Baoming, Li Pengli. Drought Resistance Comparison of Four Kinds of Vines [J]. Jiangsu Journal of Agricultural Sciences

[10] Cai Zhiwen. Expansion Bolt and Fastener [J]. Builder's Monthly, 1992, (05):24-25

[11] Tang Dengming. Application of Ornamental Vines in Landscape Architecture [J]. Jiangsu Agricultural Sciences, 2017, 45(08):127-129. 